\title{
Profiling of biological and environmental risk factors in immunogenetic subgroups of chronic lymphocytic leukemia - Czech national study
}

\author{
Kamila Stranska a,b,\#, Karla Plevova a,b,\#, Hana Skuhrova Francovaa , Hana Skabrahovaa , Magdalena von Jagwitz-Biegnitz ${ }^{\mathrm{a}}$, \\ Lenka Radova ${ }^{b}$, Anna Panovskaa , Stanislava Hrobkovaa , Yvona Brychtovaa , Renata Urbanovac, Lukas Smolej ${ }^{d}$, \\ Martin Simkovic ${ }^{d}$, Jana Zuchnicka ${ }^{e}$, Lekaa Mohammadova ${ }^{f}$, Martin Spacek ${ }^{g}$, Jiri Mayera , Sarka Pospisilova ${ }^{\mathrm{a}, \mathrm{b}}$, \\ Michael Doubek ${ }^{\mathrm{a}, \mathrm{b}}$
}

\begin{abstract}
Aims. This is a nation-wide survey of chronic lymphocytic leukemia (CLL) patients at six large hematology centers in the Czech Republic. The aim was to identify specific populations, social, and health characteristics of CLL subgroups divided according to the immunogenetic features of their B cell receptors (BCRs) and clonality.

Patients and Methods. Questionnaires directed to specific health, social, and environmental conditions were collected in a cohort of $573 \mathrm{CLL}$ patients. For these patients, immunoglobulin heavy chain gene rearrangements were also analyzed in order to gain information about their clonality, IGHV mutational status, and the presence of stereotyped BCRs. Data extracted from the questionnaires were analyzed statistically in the context of immunogenetic features of the cohort.

Results. There were no statistically significant differences in the data collected in the survey between patients with mutated and patients with unmutated IGHV. However, patients with oligoclonal CLL reported health conditions such as hypercholesterolemia, hypertension, herpes simplex, tumors, and also, separately, CLL in $1^{\text {st }}$ degree relatives, more often than their monoclonal counterparts. In patients with stereotyped BCRs, we found more frequent alcohol consumption and gastric infections in subset \#1 cases and frequent cholecystectomies and familial CLL in subset \#2 cases. Conclusion. To the best of our knowledge, this study is the first to investigate CLL immunogenetic features and clonality in the context of epidemiological data. We reported statistically significant associations suggesting the influence of certain health and social conditions on a number of clonal populations expanding in CLL and also on characteristic BCR features, especially stereotypy.
\end{abstract}

Key words: chronic lymphocytic leukemia, B-cell receptor, clonality, questionnaire, patient history, biological risk factor

Received: May 9, 2019; Revised: August 30, 2019; Accepted: September 4, 2019; Available online: September, 26, 2019 https://doi.org/10.5507/bp.2019.046

(c) 2020 The Authors; https://creativecommons.org/licenses/by/4.0/

${ }^{a}$ Department of Internal Medicine - Hematology and Oncology, University Hospital Brno and Faculty of Medicine, Masaryk University, Brno, Czech Republic

${ }^{b}$ Central European Institute of Technology, Masaryk University, Brno, Czech Republic

'Department of Hemato-Oncology, Faculty of Medicine and Dentistry, Palacky University Olomouc and University Hospital Olomouc, Czech Republic

${ }^{d} 4^{\text {th }}$ Department of Internal Medicine - Hematology, University Hospital Hradec Kralove, Hradec Kralove, Czech Republic

'Department of Hematooncology, University Hospital Ostrava, Czech Republic

${ }^{f}$ Department of Hematology and Oncology, University Hospital Pilsen, Czech Republic

${ }_{9} 7^{\text {st }}$ Department of Medicine - Department of Hematology, $1^{\text {st }}$ Faculty of Medicine, Charles University and General University Hospital in Prague, Prague, Czech Republic

"These authors contributed equally to this work

Corresponding author: Michael Doubek, e-mail: doubek.michael@fnbrno.cz

\section{INTRODUCTION}

Chronic lymphocytic leukemia (CLL) is characterized by extraordinary heterogeneity in clinical presentation, disease course and molecular features of malignant B cells. Many factors influence disease onset and course, some of which are currently used as prognostic or predictive markers. These involve specific chromosomal abnormalities ${ }^{1}$, protein expression levels ${ }^{2-5}$, gene mutations $^{6-10}$, epigenetic changes ${ }^{10}$, microRNA deregulation ${ }^{11}$, or molecular features of immunoglobulin (IG) gene rearrangements ${ }^{2,12,13}$. In addition to cell-intrinsic features, microenvironment also represents a prominent factor in disease development ${ }^{14,15}$.

Since CLL is a clonal disease of mature B cells, each case can be described by a unique set of IG rearrangements that encode for the B-cell receptor (BCR). In a clinical setting, somatic hypermutation load in the IG heavy chain variable region (IGHV) is routinely examined as this reliably divides patients into two prognosti- 
cally distinct groups ${ }^{2,13}$. Antigen stimulation is generally accepted as a prerequisite for the expansion of clonal B-cell populations. The striking degree of BCR sequence similarity observed between unrelated cases in one-third of patients ${ }^{16}$ suggests promoting pressure leading to CLL clone selection caused by a shared set of antigen epitopes. In this context, various antigens/epitopes recognized by CLL BCRs have been described. Most of them are autoantigens presented during apoptosis and inflammation ${ }^{17-19}$, or surface antigens of stromal cells ${ }^{20,21}$ and $\mathrm{B}$ cells ${ }^{22}$ but several exogenous bacterial, viral, and fungal antigens have been proposed as well ${ }^{19,23-26}$. In addition to that, CLL BCRs have been shown to interact in BCR-binding epitopes within IG heavy and light chain, enabling autonomous BCR signaling ${ }^{27,28}$. Of note, CLL BCRs with mutated IGHV and those with unmutated IGHV differ in the level of their responsiveness to stimulation, with mutated BCRs showing reduced activation of the signaling response, and also in interactions with antigens, with unmutated BCRs being more polyreactive and more frequently binding autoantigens $\mathrm{s}^{15,29,30}$. Furthermore, despite the generally monoclonal nature of the disease, CLL comprising several leukemic clones with different BCRs can be observed in up to a quarter of CLL cases, depending on the detection method used ${ }^{31-33}$. Expansion of multiple clones in such cases raises the question of whether these clones might proliferate upon chronic stimulation by antigens present in a case.

In line with molecular observations, epidemiological studies showed that prior to diagnosis, CLL patients experience some common infections more frequently than controls $^{34-37}$. Increased risk of CLL development was also documented for several autoimmune and chronic inflammatory diseases ${ }^{35,38}$. Notably, chronic stimulation in general (including both autoimmune diseases and chronic infections) in CLL is associated with unfavorable cytogenetics and unmutated IGHV (ref. ${ }^{39}$ ). CLL occurrence has also been connected with several occupational and environmental exposures ${ }^{37,40}$. Among first-degree relatives of CLL patients, there is an increased risk of the same malignancy or other lymphoproliferative diseases ${ }^{37,41-44}$. To our best knowledge, however, there has been only one epidemiologic study published to date that took into consideration immunogenetic features of the investigated CLL cases $^{39}$ and no study taking the CLL clonality into account.

In this work, we employed a carefully designed questionnaires in a nation-wide survey among CLL patients of six large Czech hematological centers to reveal specific population, social, and health characteristics of subgroups of CLL patients distinguished primarily by their immunogenetic features and clonality. Our aim was to gain insight into antigen stimuli and other influences in individual CLL patients, that could be reflected in the selection and character of IG rearrangement of a leukemic clone.

\section{METHODS}

\section{CLL patients}

The study was performed on 573 consecutive CLL patients treated or monitored at one of the six large collaborating Czech hematological centers (University Hospital Brno, University Hospital Hradec Králové, General University Hospital Prague, University Hospital Olomouc, University Hospital Pilsen and University Hospital Ostrava) between years 2014-2018. All patients fulfilled the iwCLL/NCI diagnostic criteria for CLL ( ref. $^{45}$ ), and completed questionnaires and the results of IGH analysis were obtained from all of them. All blood samples and questionnaires were taken after written informed patient's consent in accordance with the Declaration of Helsinki, under protocols approved by the Ethical Committees of all involved institutions. Standard CLL-related clinical and laboratory parameters (age at diagnosis, sex, time to first treatment, overall survival, clinical stage at diagnosis, cytogenetic aberrations, TP53 mutation status) obtained from the Czech national CLL database CLLEAR, where all involved hematological centers contributed, were paired with respective questionnaires.

\section{Analysis of clonal IGH rearrangements}

Negative B lymphocyte separation, total RNA isolation, cDNA synthesis, and IGHV mutational status analysis by direct Sanger sequencing were performed for all patients involved in the study as previously described $^{31,32}$. PCR/Sanger analysis was complemented by IGH fragment analysis and also by subcloning when necessary. Stereotyped BCRs were identified using ARResT/ AssignSubsets tool ${ }^{46}$, enabling assignment to the 19 major stereotyped CLL subsets ${ }^{16}$.

\section{Analysis of cytogenetic aberrations and TP53 mutations}

The presence TP53 mutation was analyzed by Sanger sequencing ${ }^{47}$ and/or next-generation sequencing ${ }^{48}$. The hierarchical classification of four common cytogenetic aberrations ${ }^{1}$ was analyzed by fluorescence in situ hybridization as described elsewhere ${ }^{49,50}$.

\section{Questionnaires}

Questionnaires were filled in with the assistance of a clinician. They were designed to obtain information on basic characteristics of a patient (sex, age, date of birth), social and work history (marital status, number of children, living alone, profession), alcohol consumption and cigarette smoking, personal medical history (metabolic diseases, cardiovascular and respiratory diseases, chronic infections, autoimmune diseases and rheumatic disorders, allergies, surgical history, oncological diseases), and family history (oncological and autoimmune diseases). Most questions on basic patient characteristics and social and work history were open-ended. The rest of the questions had standardized closed-ended answers, either dichotomous (yes/no) with space for specification, or polytomous (alcohol drinking: never, occasionally, regularly; smoking: yes, no, stop-smoker). The questionnaire form is provided in the Supplementary material. 


\section{Statistics}

Clinical characteristics and data from collected questionnaires were compared between the cohorts of monoclonal CLL and oligoclonal CLL, and their subgroups based on the IGHV mutational status; the most numerous subsets of stereotyped BCRs were compared to a respective monoclonal subgroup (with either mutated, or unmutated IGHV; the exception was the subset \#2, which we compared to both monoclonal subgroups separately and also to overall monoclonal cohort, as it contains both mutated and unmutated cases): The two-tailed MannWhitney U test and the Kruskal-Wallis test followed by the Dunn post hoc test were used to compare age at diagnosis; log-rank (Mantel-Cox) test and the Wald test were used for time to first treatment (TTFT) and overall survival (OS) comparisons; the two-tailed Mann-Whitney U test and the Kruskal-Wallis test were used for comparing the number of children; all other categories were tested by two-tailed Fisher's exact test. Value $P<0.05$ was considered as a threshold for statistical significance in all comparisons. All analyses were performed in R.

\section{RESULTS}

\section{Composition of the cohort and immunogenetic findings}

In total, 573 CLL patients, from which both filled questionnaires and IGHV analysis results were collected, were included in the study. The cohort was composed of 343 men and 230 women, with median age at diagnosis 63.6 years (range 33.2-90.3 years). Median TTFT of the cohort was 47.4 months, median OS was 269.6 months. Basic characteristics of the cohort are summarized in Table 1. Three hundred and twenty-two (322) patients filled the questionnaire before first treatment, 229 patients after it.

Analysis of the clonal IGH rearrangements divided patients into several subgroups: whereas 518 patients (90.4\%) had a monoclonal form of the disease, in 55 patients $(9.6 \%)$ more than one clone was detected. Two hundred thirty-nine (239) monoclonal patients had their IGHV mutated (monoM), and 279 unmutated (monoU). In the oligoclonal group of patients, 18 had concordantly mutated clones (oligoM), 16 concordantly unmutated (oligoU), and the remaining 21 patients had coexisting clones with discordant IGHV mutational status (oligoD). Seventy-five (75) patients of the whole cohort had at least one clone belonging into one of the 19 major CLL subsets with stereotyped BCR. However, only subsets \#1 and \#2 were sufficiently numerous ( 19 and 18 cases, respectively) to be suitable for most comparisons - for several other subsets (\#202: 5 cases; \#3, \#14, and \#99: 4 cases each) only the most striking results had the chance to came out as significant.

Detailed information on the cohort composition and results extracted from the questionnaires are summarized in Supplementary Table 1.

\section{Social and health conditions do not influence IGHV mutational status in monoclonal CLL}

MonoM and monoU groups showed statistically significant differences in all compared clinical and laboratory categories (female/male ratio, age and Rai stage at diagnosis, FISH aberrations, TP53 mutations, TTFT, OS) in concordance with published data, with adverse parameters being more frequent in the monoU group (Table 2). This observation illustrates that our cohort was representative and suitable for further analyses.

With regards to information collected from the questionnaires, there were no statistically significant differences in external factors or family disease burden between monoM and monoU cases (Supplementary Table 2). Only two nearly significant tendencies were encountered - in monoU cases autoimmune diseases were more frequent in either patients themselves $(P=0.0786)$ or in their $1^{\text {st }}$ degree family relatives $(P=0.0615)$.

\section{Specific health conditions are frequent in oligoclonal CLL}

In the next step, we compared questionnaire findings between monoclonal and oligoclonal CLL cases (Table 2, Supplementary Table 2). No statistically significant differences in clinical parameters of the groups were noted with the only exception of patient age at diagnosis - oligoclonal CLL cases were typically older (median age at diagnosis 65.7 vs 63.3 years, $P=0.03577$ ). Interestingly, several health conditions were more frequent in oligoclonal cases. Patients with oligoclonal CLL more often reported hypercholesterolemia $(P=0.0047)$, hypertension ( $P=0.01442)$, herpes simplex $(P=0.33195)$, and tumors in $1^{\text {st }}$ degree relatives $(P=0.03278)$ - the latter retained statistical significance even when limited to CLL only $(P=0.02104)$.

When categorized according to the IGHV mutational status, as expected, oligoM and oligoU cases showed similar clinico-biological behavior to their monoclonal counterparts. Considering the questionnaire data, oligoM cases featured increased frequency of non-smokers compared to oligoU group ( $P=0.0209$ ), and compared to both monoU and monoM groups they frequently reported hypertension $(P=0.025 ; P=0.0249)$ and hematooncological diseases in family ( $P=0.0347 ; P=0.0402$; when limited to CLL: $P=0.0312 ; P=0.079)$. In oligoU group there were no significant differences compared to both monoU and monoM. Patients from oligoD group reported hypercholesterolemia the most often among all other groups tested (vs monoM $P=0.00084$; vs monoU $P=0.00007$; vs oligoM $P=0.0549$; vs oligoU $P=0.0233$ ).

\section{Stereotyped CLL subsets are associated with specific medical conditions}

We also investigated whether the presence of stereotyped BCRs associates with specific biological features in the tested cohort. Subset \#1 patients more often reported occasional alcohol consumption $(P=0.02749)$ and less abstinence $(P=0.01379)$ compared to the rest of monoU CLL. Interestingly, this observation was accompanied by more chronic infections of the digestive system, in- 


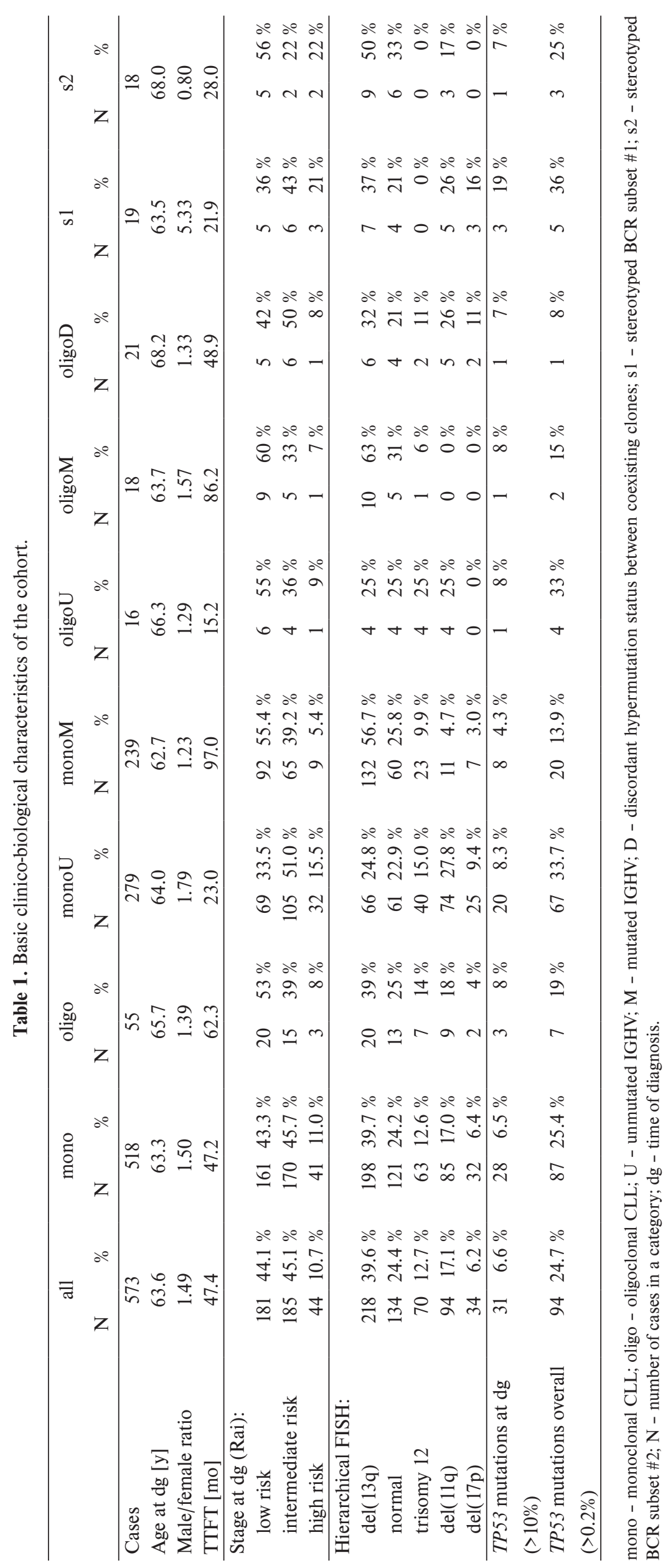




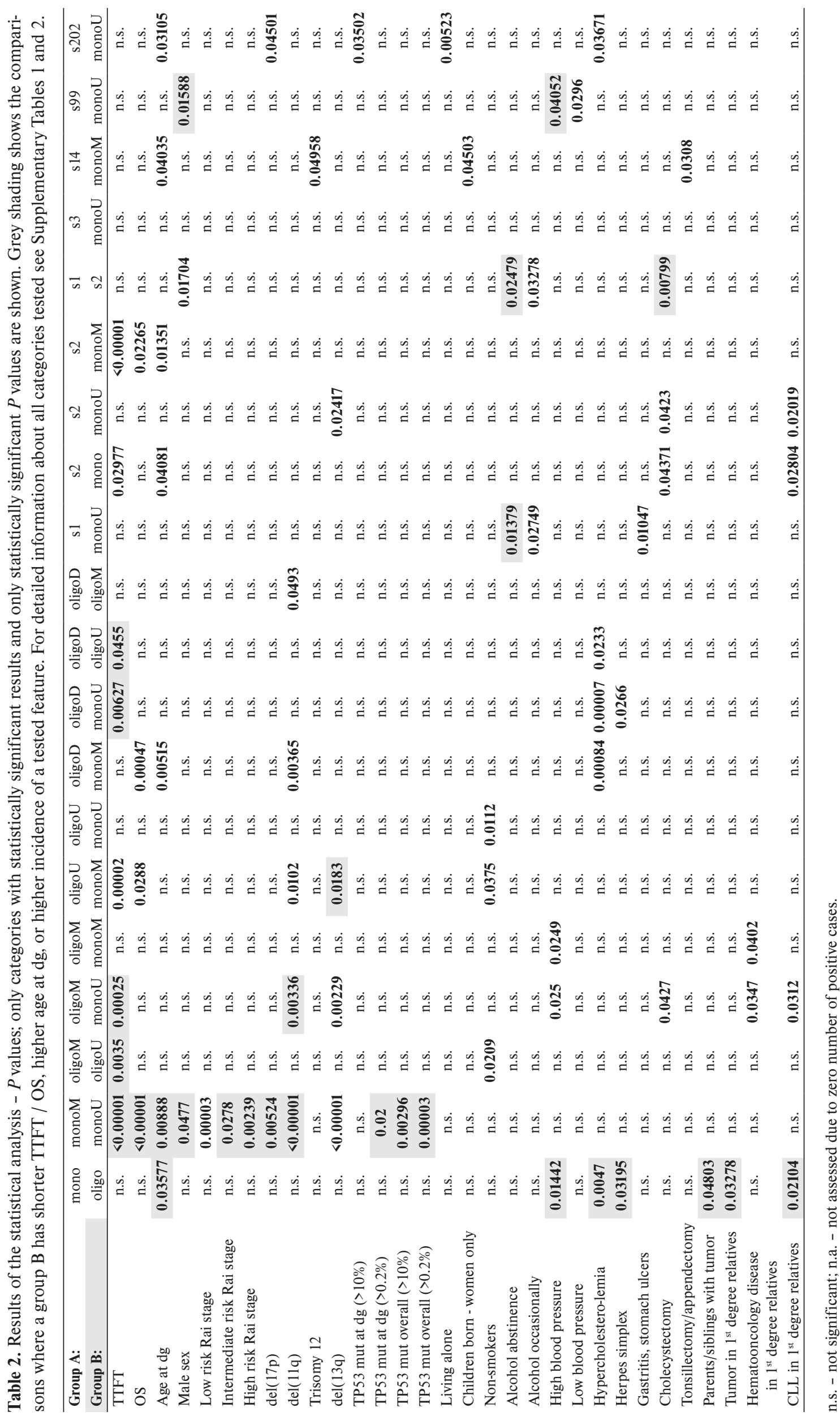


cluding gastritis and stomach ulcers in subset \#1 patients $(P=0.01047)$.

Subset \#2 patients tended to undergo cholecystectomies more often than other CLL patients (vs all mono $P=0.04371$; vs monoU $P=0.0423$; vs monoM $P=0.0905$ ). They had also a high prevalence of CLL among their relatives (vs all mono $P=0.02803$; vs monoU $P=0.2018$; vs monoM $P=0.06327$ ).

In less abundant CLL stereotyped subsets in our cohort, we identified the following differences: Four of 5 subset \#202 patients reported living alone $(P=0.00523)$, the same number reported hypercholesterolemia $(P=0.03671)$, and albeit non-significant, all cases of this subset reported hypertension $(P=0.06651)$. All patients of subset \#99 were women $(P=0.01588)$. Three out of the 4 reported rheumatic disorders (not significant: $P=0.05002$ ); significant differences were observed in high blood pressure with 2 out of the 4 patients reporting hypotension $(P=0.0296)$ and none of them hypertension $(P=0.04052)$. All cases of subset \#14 reported tonsilectomies and/or appendix surgery $(P=0.0308)$. No statistically significant difference in patient history data was observed for stereotyped subset \#3.

\section{DISCUSSION}

In the present study, we aimed to elucidate which environmental, lifestyle, health and other factors might influence CLL clonal selection with respect to specific features of CLL BCRs. For this purpose, we surveyed 573 CLL patients monitored in six large hematology centers across the Czech Republic. The distributed questionnaire contained mostly questions with dichotomic answers to facilitate easy responding, and afterwards, straightforward processing of the data. Nevertheless, during the extraction of data from the questionnaires, we faced issues caused by question misunderstanding or inadequate knowledge of patients' and their family members' health conditions, resulting in a potential burden of subjective responses which we tried to reduce by further investigation of patients' clinical records and direct surveying the patients and their accompanying relatives. Furthermore, some questions were eventually excluded from the final analysis as we did not collect enough valid data. This issue mainly concerned patient vaccination and childhood illnesses as these were the categories which patients mostly did not remember. Still we believe that our study has provided valuable insight into the real world CLL population and their native environment.

In the published data it is widely appreciated that specific environmental stimuli, social habits, and health conditions are present in CLL patients with increased occurrence compared to healthy age-matched controls ${ }^{35-37}$. On the other hand, to our best knowledge, no study has been published that would investigate the correlation of patient CLL immunogenetic features of their clonotypic BCR with patient history data. There are a handful of studies which touched upon a comparison of IGHV mutated and unmutated CLL subgroups ${ }^{39,51,52}$. A similar study focusing on CLL clonality and the presence of stereotyped BCR subsets has not been published to date. In this respect our study attempts to fill the gap in the current knowledge about CLL clonal selection and onset.

The whole collected cohort was representative of the general CLL population. In monoclonal CLL cases surveyed in this study we observed all differences in clinical and laboratory parameters that are expected between IGHV mutated and unmutated subgroups ${ }^{2,13,53}$. Considering questionnaire data obtained for the subgroups we did not find any statistically significant differences. We observed only a weak, statistically insignificant association between unmutated IGHV and the occurrence of autoimmune diseases. This association is partly in agreement with observation by Vanura et al. (ref. ${ }^{39}$ ) who found increased frequency of autoimmune diseases in female CLL patients with unmutated IGHV. Analysis of larger cohort would be needed to confirm the association. Nevertheless, overall, our findings indicate that extrinsic stimuli likely do not affect to a large extent whether IGHV mutated or unmutated clone would expand.

Further, we focused on clonality in our CLL cohort. We collected 55 CLL cases with oligoclonal disease (9.6\% of the cohort) which was sufficient for statistical analysis of patient history data. In published studies, oligoclonal CLL has been observed in 2 to $24.4 \%$ of cases, depending on the detection method used ${ }^{31-33,54}$. Prognostication of these oligoclonal cases may be challenging, especially in cases of coexisting clones with discordant IGHV mutational status ${ }^{54}$, and in this area, only limited work has so far been reported ${ }^{31-33,55}$. For the IGH rearrangement analysis within the current study, we used Sanger sequencing which has typically lower detection rate of multiple rearrangements. From this point of view, capturing nearly $10 \%$ of oligoclonal cases in our cohort is quite high but still within an acceptable range. We did not find any differences concerning clinical and laboratory status between oligoclonal and monoclonal cases with the exception of age at diagnosis. This observation confirms the results of our previous studies on oligoclonal CLL (ref. ${ }^{31,32}$ ). Admittedly there was a partial overlap between the cohorts but the difference in age stayed significant even after adding new cases from other workplaces included in the present cohort.

In agreement with other studies ${ }^{31,33,55}$, we observed concordant IGHV mutational status of coexisting clones in almost two-thirds of oligoclonal cases $(34 / 55 ; 62 \%)$. The remarkably high occurrence of concordant IGHV mutational status in oligoclonal cases suggests that coexisting clones experienced the same or similar influences affecting their development. According to the recent evidence, shared epitope reactivity ${ }^{56}$ or origin from a common cellular progenitor ${ }^{57,58}$ might be such influences. Here we found health conditions, such as hypercholesterolemia, hypertension, herpes simplex, and tumors in $1^{\text {st }}$ degree relatives, more frequent in oligoclonal cases than the monoclonal ones. Out of these only hypercholesterolemia was reported to precede a CLL diagnosis with a higher prevalence compared with control subjects ${ }^{59}$. Particularly, the higher prevalence of CLL in the families 
of our oligoclonal CLL cases poses an interesting basis for further investigation of shared antigenic stimuli and possible genetic background in CLL families. An observation indicative of similar findings was also gained in monoclonal B lymphocytosis ${ }^{60}$ where a high occurrence of multiclonal cases was noted ${ }^{61}$.

Finally, stereotyped BCR subsets were reported to share many clinico-biological features, for example, the presence of prognostically relevant gene mutations and cytogenetic aberrations, or clinical aggressiveness of the disease ${ }^{12,51,62-65}$. Thus, we were interested in whether this clinical similarity might be reflected in common extrinsic influences. The number of stereotyped BCR subsets in our cohort precluded extensive analyses of this phenomenon, however, still for subsets \#1 and \#2 we collected enough cases and obtained results worth further interest. Namely, subset \#1 patients more often reported occasional alcohol consumption compared to the rest of monoU CLL and also more chronic infections of the digestive system which can create an antigenic pressure due to chronic inflammation known mainly from other lymphoid malignancies ${ }^{66}$. In subset \#2 patients, we observed frequent cholecystectomies more often than in other CLL patients and high prevalence of CLL in their families. All these observations have not been reported previously and represent novel findings of our study. The last subset worth mentioning is subset \#99 with unmutated IGHV1 rearrangements consisting exclusively of women wherein the majority of subjects reported rheumatoid diseases, markedly reminiscent of female patients with unmutated IGHV and autoimmune conditions reported elsewhere ${ }^{39}$.

\section{CONCLUSIONS}

Thorough analysis of both biological features and clinical course in each CLL case facilitates a more personalized approach in patient care and enables the formation of homogeneous patients' groups for answering many important clinical and research questions. To our knowledge, our study is the first to investigate CLL immunogenetic features and clonality in the context of patient history data. We reported several statistically significant associations suggesting the influence of certain health and social conditions on a number of clonal populations expanded in CLL. Specifically, patients with oligoclonal CLL reported hypercholesterolemia, hypertension, herpes simplex, and tumors (and separately also CLL) in $1^{\text {st }}$ degree relatives more often than patients with monoclonal disease. With regards to stereotyped BCR, subset \#1 patients often reported occasional alcohol consumption and chronic infections of the digestive system, and subset \#2 patients underwent cholecystectomies more often than other CLL patients. Our study only refers to potential relationships of the given conditions to CLL immunogenetic subgroups, which needs to be validated further. However, it may form the basis for future epidemiological studies that would clarify conclusively the observed associations.

\section{ABBREVIATIONS}

CLL, Chronic lymphocytic leukemia; BCR, B cell receptor; mono, monoclonal; oligo, oligoclonal; IG, Immunoglobulin; IGHV, IG heavy chain variable region; U, Unmutated; M, Mutated; D, Discordant; TTFT, Tme to first treatment; OS, Overall survival.

Acknowledgement: Supported by Research Grant AZV 15-30015A of Ministry of Health, Czech Republic. All rights reserved. The authors thank Barbara Vonkova for questionnaire translation and Francesco Daniel Muto for language editing throughout the whole manuscript.

Author contributions: KP, MD: designed questionnaires; LS, MSi, MSp, RU, JZ, LM, AP, SH, YB, JM, MD: provided samples, clinical data, and collected questionnaires; HSk: administered questionnaires; KS, MvJB: processed questionnaires; HSF, KS: performed immunogenetic analyses; KS, LR: performed statistical analyses; KS, KP: wrote the manuscript; SP, MD: revised manuscript; KP, SP, MD: supervised the study.

Conflict of interest statement: The authors state that there are no conflicts of interest regarding the publication of this article.

\section{REFERENCES}

1. Dohner H, Stilgenbauer S, Benner A, Leupolt E, Krober A, Bullinger L, Dohner K, Bentz M, Lichter P. Genomic aberrations and survival in chronic lymphocytic leukemia. N Engl J Med 2000;343(26):1910-6.

2. Damle RN, Wasil T, Fais F, Ghiotto F, Valetto A, Allen SL, Buchbinder A, Budman D, Dittmar K, Kolitz J, Lichtman SM, Schulman P, Vinciguerra VP, Rai KR, Ferrarini M, Chiorazzi N. Ig V gene mutation status and CD38 expression as novel prognostic indicators in chronic lymphocytic leukemia. Blood 1999;94(6):1840-7.

3. Rassenti LZ, Huynh L, Toy TL, Chen L, Keating MJ, Gribben JG, Neuberg DS, Flinn IW, Rai KR, Byrd JC, Kay NE, Greaves A, Weiss A, Kipps TJ. ZAP-70 compared with immunoglobulin heavy-chain gene mutation status as a predictor of disease progression in chronic lymphocytic leukemia. N Engl J Med 2004;351(9):893-901.

4. Robertson LE, Plunkett W, McConnell K, Keating MJ, McDonnell TJ. $\mathrm{BCl}-2$ expression in chronic lymphocytic leukemia and its correlation with the induction of apoptosis and clinical outcome. Leukemia 1996;10(3):456-9.

5. Ferreira PG, Jares P, Rico D, Gomez-Lopez G, Martinez-Trillos A, Villamor N, Ecker S, Gonzalez-Perez A, Knowles DG, Monlong J, Johnson R, Quesada V, Djebali S, Papasaikas P, Lopez-Guerra M, Colomer D, Royo C, Cazorla M, Pinyol M, Clot G, Aymerich M, Rozman M, Kulis M, Tamborero D, Gouin A, Blanc J, Gut M, Gut I, Puente XS, Pisano DG, Martin-Subero Jl, Lopez-Bigas N, Lopez-Guillermo A, Valencia A, Lopez-Otin C, Campo E, Guigo R. Transcriptome characterization by RNA sequencing identifies a major molecular and clinical subdivision in chronic lymphocytic leukemia. Genome Res 2014;24(2):212-26.

6. Oscier DG, Rose-Zerilli MJ, Winkelmann N, de Castro D, Gomez B, Forster J, Parker H, Parker A, Gardiner A, Collins A, Else M, Cross NC, Catovsky D, Strefford JC. The clinical significance of NOTCH1 and SF3B1 mutations in the UK LRF CLL4 trial. Blood 2013;121(3):468-75.

7. Rossi D, Rasi S, Spina V, Bruscaggin A, Monti S, Ciardullo C, Deambrogi C, Khiabanian H, Serra R, Bertoni F, Forconi F, Laurenti L, Marasca R, Dal-Bo M, Rossi FM, Bulian P, Nomdedeu J, Del Poeta G, Gattei V, Pasqualucci L, Rabadan R, Foa R, Dalla-Favera R, Gaidano $\mathrm{G}$. Integrated mutational and cytogenetic analysis identifies new prognostic subgroups in chronic lymphocytic leukemia. Blood 2013;121(8):1403-12. 
8. Zenz T, Eichhorst B, Busch R, Denzel T, Habe S, Winkler D, Buhler A, Edelmann J, Bergmann M, Hopfinger G, Hensel M, Hallek M, Dohner $\mathrm{H}$, Stilgenbauer S. TP53 mutation and survival in chronic lymphocytic leukemia. J Clin Oncol 2010;28(29):4473-9.

9. Rossi D, Ciardullo C, Spina V, Gaidano G. Molecular bases of chronic lymphocytic leukemia in light of new treatments. Immunol Lett 2013;155(1-2):51-5.

10. Guieze R, Wu CJ. Genomic and epigenomic heterogeneity in chronic lymphocytic leukemia. Blood 2015;126(4):445-53.

11. Balatti V, Pekarky Y, Croce CM. Role of microRNA in chronic lymphocytic leukemia onset and progression. J Hematol Oncol 2015;8:12.

12. Baliakas $P$, Hadzidimitriou $A$, Sutton $L A$, Minga $E$, Agathangelidis A, Nichelatti M, Tsanousa A, Scarfo L, Davis Z, Yan XJ, Shanafelt T, Plevova K, Sandberg Y, Vojdeman FJ, Boudjogra M, Tzenou T, Chatzouli M, Chu CC, Veronese S, Gardiner A, Mansouri L, Smedby KE, Pedersen LB, van Lom K, Giudicelli V, Francova HS, NguyenKhac F, Panagiotidis P, Juliusson G, Angelis L, Anagnostopoulos A Lefranc MP, Facco M, Trentin L, Catherwood M, Montillo M, Geisler $\mathrm{CH}$, Langerak AW, Pospisilova S, Chiorazzi N, Oscier D, Jelinek DF, Darzentas N, Belessi C, Davi F, Rosenquist R, Ghia P, Stamatopoulos K. Clinical effect of stereotyped B-cell receptor immunoglobulins in chronic lymphocytic leukaemia: a retrospective multicentre study. Lancet Haematol 2014;1(2):e74-84.

13. Hamblin TJ, Davis Z, Gardiner A, Oscier DG, Stevenson FK. Unmutated $\lg \mathrm{V}(\mathrm{H})$ genes are associated with a more aggressive form of chronic lymphocytic leukemia. Blood 1999;94(6):1848-54.

14. Herishanu Y, Perez-Galan P, Liu D, Biancotto A, Pittaluga S, Vire B, Gibellini F, Njuguna N, Lee E, Stennett L, Raghavachari N, Liu P, McCoy JP, Raffeld M, Stetler-Stevenson M, Yuan C, Sherry R, Arthur DC, Maric I, White T, Marti GE, Munson P, Wilson WH, Wiestner A. The lymph node microenvironment promotes B-cell receptor signaling, NF-kappaB activation, and tumor proliferation in chronic lymphocytic leukemia. Blood 2011;117(2):563-74.

15. Ten Hacken E, Burger JA. Microenvironment interactions and B-cell receptor signaling in Chronic Lymphocytic Leukemia: Implications for disease pathogenesis and treatment. Biochim Biophys Acta 2016;1863(3):401-13.

16. Agathangelidis A, Darzentas N, Hadzidimitriou A, Brochet X, Murray F, Yan XJ, Davis Z, van Gastel-Mol EJ, Tresoldi C, Chu CC, Cahill N, Giudicelli V, Tichy B, Pedersen LB, Foroni L, Bonello L, Janus A, Smedby K, Anagnostopoulos A, Merle-Beral H, Laoutaris N, Juliusson G, di Celle PF, Pospisilova S, Jurlander J, Geisler C, Tsaftaris A, Lefranc MP, Langerak AW, Oscier DG, Chiorazzi N, Belessi C, Davi F, Rosenquist R, Ghia P, Stamatopoulos K. Stereotyped B-cell receptors in one-third of chronic lymphocytic leukemia: a molecular classification with implications for targeted therapies. Blood 2012;119(19):4467-75.

17. Catera R, Silverman GJ, Hatzi K, Seiler T, Didier S, Zhang L, Herve M, Meffre E, Oscier DG, Vlassara H, Scofield RH, Chen Y, Allen SL, Kolitz J, Rai KR, Chu CC, Chiorazzi N. Chronic lymphocytic leukemia cells recognize conserved epitopes associated with apoptosis and oxidation. Mol Med 2008;14(11-12):665-74.

18. Chu CC, Catera R, Zhang L, Didier S, Agagnina BM, Damle RN Kaufman MS, Kolitz JE, Allen SL, Rai KR, Chiorazzi N. Many chronic lymphocytic leukemia antibodies recognize apoptotic cells with exposed nonmuscle myosin heavy chain IIA: implications for patient outcome and cell of origin. Blood 2010;115(19):3907-15.

19. Lanemo Myhrinder A, Hellqvist E, Sidorova E, Soderberg A, Baxendale H, Dahle C, Willander K, Tobin G, Backman E, Soderberg O, Rosenquist R, Horkko S, Rosen A. A new perspective: molecular motifs on oxidized LDL, apoptotic cells, and bacteria are targets for chronic lymphocytic leukemia antibodies. Blood 2008;111(7):383848.

20. Binder M, Lechenne B, Ummanni R, Scharf C, Balabanov S, Trusch M, Schluter H, Braren I, Spillner E, Trepel M. Stereotypical chronic lymphocytic leukemia B-cell receptors recognize survival promoting antigens on stromal cells. PLoS One 2010;5(12):e15992.

21. ten Hacken E, Gounari M, Back JW, Shimanovskaya E, Scarfo L, Kim E, Burks J, Ponzoni M, Ramirez GA, Wierda WG, Estrov Z, Keating MJ, Ferrajoli A, Stamatopoulos K, Ghia P, Burger JA. Calreticulin as a novel B-cell receptor antigen in chronic lymphocytic leukemia. Haematologica 2017;102(10):e394-6.

22. Catera R, Liu Y, Gao C, Yan XJ, Magli A, Allen SL, Kolitz JE, Rai KR, Chu CC, Feizi T, Stamatopoulos K, Chiorazzi N. Binding of CLL subset 4 B-cell receptor immunoglobulins to viable human memory B lym- phocytes requires a distinctive IGKV somatic mutation. Mol Med 2017:23:1-12.

23. Hoogeboom R, van Kessel KP, Hochstenbach F, Wormhoudt TA, Reinten RJ, Wagner K, Kater AP, Guikema JE, Bende RJ, van Noesel CJ. A mutated B cell chronic lymphocytic leukemia subset that recognizes and responds to fungi. J Exp Med 2013;210(1):59-70.

24. Hwang KK, Trama AM, Kozink DM, Chen X, Wiehe K, Cooper AJ, Xia SM, Wang M, Marshall DJ, Whitesides J, Alam M, Tomaras GD, Allen SL, Rai KR, McKeating J, Catera R, Yan XJ, Chu CC, Kelsoe G, Liao HX, Chiorazzi N, Haynes BF. IGHV1-69 B cell chronic lymphocytic leukemia antibodies cross-react with HIV-1 and hepatitis $C$ virus antigens as well as intestinal commensal bacteria. PLoS One 2014;9(3):e90725.

25. Que X, Widhopf G. F. 2nd, Amir S, Hartvigsen K, Hansen LF, Woelkers D, Tsimikas S, Binder CJ, Kipps TJ, Witztum JL. IGHV1-69-encoded antibodies expressed in chronic lymphocytic leukemia react with malondialdehyde-acetaldehyde adduct, an immunodominant oxidation-specific epitope. PLoS One 2013;8(6):e65203.

26. Steininger C, Widhopf G. F. 2nd, Ghia EM, Morello CS, Vanura K Sanders R, Spector D, Guiney D, Jager U, Kipps TJ. Recombinant antibodies encoded by IGHV1-69 react with pUL32, a phosphoprotein of cytomegalovirus and B-cell superantigen. Blood 2012;119(10):2293301.

27. Duhren-von Minden $M$, Ubelhart R, Schneider D, Wossning T, Bach MP, Buchner M, Hofmann D, Surova E, Follo M, Kohler F, Wardemann $\mathrm{H}$, Zirlik K, Veelken H, Jumaa H. Chronic lymphocytic leukaemia is driven by antigen-independent cell-autonomous signalling. Nature 2012:489(7415):309-12.

28. Minici C, Gounari M, Ubelhart R, Scarfo L, Duhren-von Minden $M$, Schneider D, Tasdogan A, Alkhatib A, Agathangelidis A, Ntoufa S, Chiorazzi N, Jumaa H, Stamatopoulos K, Ghia P, Degano M. Distinct homotypic B-cell receptor interactions shape the outcome of chronic lymphocytic leukaemia. Nat Commun 2017;8:15746.

29. Herve M, Xu K, Ng YS, Wardemann H, Albesiano E, Messmer BT, Chiorazzi N, Meffre E. Unmutated and mutated chronic lymphocytic leukemias derive from self-reactive $B$ cell precursors despite expressing different antibody reactivity. J Clin Invest 2005;115(6):1636-43.

30. Seiler T, Woelfle M, Yancopoulos S, Catera R, Li W, Hatzi K, Moreno C, Torres M, Paul S, Dohner H, Stilgenbauer S, Kaufman MS, Kolitz JE, Allen SL, Rai KR, Chu CC, Chiorazzi N. Characterization of structurally defined epitopes recognized by monoclonal antibodies produced by chronic lymphocytic leukemia B cells. Blood 2009;114(17):361524.

31. Brazdilova K, Plevova K, Skuhrova Francova H, Kockova H, Borsky M, Bikos V, Malcikova J, Oltova A, Kotaskova J, Tichy B, Brychtova Y, Mayer J, Doubek M, Pospisilova S. Multiple productive IGH rearrangements denote oligoclonality even in immunophenotypically monoclonal CLL. Leukemia 2018;32(1):234-6.

32. Plevova K, Francova HS, Burckova K, Brychtova Y, Doubek M, Pavlova S, Malcikova J, Mayer J, Tichy B, Pospisilova S. Multiple productive immunoglobulin heavy chain gene rearrangements in chronic lymphocytic leukemia are mostly derived from independent clones. Haematologica 2014;99(2):329-38.

33. Stamatopoulos B, Timbs A, Bruce D, Smith T, Clifford R, Robbe $P$ Burns A, Vavoulis D V, Lopez L, Antoniou P, Mason J, Dreau H, Schuh A. Targeted deep sequencing reveals clinically relevant subclonal IgHV rearrangements in chronic lymphocytic leukemia. Leukemia 2017;31(4):837-45.

34. Anderson LA, Landgren O, Engels EA. Common community acquired infections and subsequent risk of chronic lymphocytic leukaemia. Br J Haematol 2009;147(4):444-9.

35. Landgren O, Gridley G, Check D, Caporaso NE, Morris Brown L. Acquired immune-related and inflammatory conditions and subsequent chronic lymphocytic leukaemia. Br J Haematol 2007;139(5):791-8.

36. Landgren O, Rapkin JS, Caporaso NE, Mellemkjaer L, Gridley G, Goldin LR, Engels EA. Respiratory tract infections and subsequent risk of chronic lymphocytic leukemia. Blood 2007;109(5):2198-201.

37. Slager SL, Benavente $Y$, Blair A, Vermeulen R, Cerhan JR, Costantin AS, Monnereau A, Nieters A, Clavel J, Call TG, Maynadie M, Lan Q, Clarke CA, Lightfoot T, Norman AD, Sampson JN, Casabonne D, Cocco P, de Sanjose S. Medical history, lifestyle, family history, and occupational risk factors for chronic lymphocytic leukemia/small lymphocytic lymphoma: the InterLymph Non-Hodgkin Lymphoma Subtypes Project. J Natl Cancer Inst Monogr 2014;2014(48):41-51. 
38. Soderberg KC, Jonsson F, Winqvist O, Hagmar L, Feychting M. Autoimmune diseases, asthma and risk of haematological malignancies: a nationwide case-control study in Sweden. Eur J Cancer 2006;42(17):3028-33

39. Vanura K, Le T, Esterbauer H, Spath F, Porpaczy E, Shehata M, Eigenberger K, Hauswirth A, Skrabs C, Kromer E, Schwarzinger I, Streubel B, Steininger C, Fonatsch C, Stilgenbauer S, Wagner O, Gaiger A, Jager U. Autoimmune conditions and chronic infections in chronic lymphocytic leukemia patients at diagnosis are associated with unmutated IgVH genes. Haematologica 2008;93(12):1912-6.

40. Karakosta M, Delicha EM, Kouraklis G, Manola KN. Association of various risk factors with chronic lymphocytic leukemia and its cytogenetic characteristics. Arch Env Occup Heal 2016;71(6):317-29.

41. Benavente Y, Casabonne D, Costas L, Robles C, Alonso E, de la Banda E, Gonzalez-Barca E, Marcos-Gragera R, Llorca J, Tardon A, Monleon J, Aymerich M, Campo E, Gimeno-Vazquez E, Castano-Vinyals G, Aragones N, Pollan M, Kogevinas M, de Sanjose S. Established and suggested exposures on CLL/SLL etiology: Results from the CLLMCC-Spain study. Cancer Epidemiol 2018;52:106-11.

42. Brown JR, Neuberg D, Phillips K, Reynolds H, Silverstein J, Clark JC, Ash M, Thompson C, Fisher DC, Jacobsen E, LaCasce AS, Freedman AS. Prevalence of familial malignancy in a prospectively screened cohort of patients with lymphoproliferative disorders. Br J Haematol 2008;143(3):361-8.

43. Goldin LR, Bjorkholm M, Kristinsson SY, Turesson I, Landgren O. Elevated risk of chronic lymphocytic leukemia and other indolent non-Hodgkin's lymphomas among relatives of patients with chronic lymphocytic leukemia. Haematologica 2009;94(5):647-53.

44. Rebora P, Lee M, Czene K, Valsecchi MG, Reilly M. High risks of familial chronic lymphatic leukemia for specific relatives: signposts for genetic discovery? Leukemia 2012;26(11):2419-21.

45. Hallek M, Cheson BD, Catovsky D, Caligaris-Cappio F, Dighiero G, Döhner H, Hillmen P, Keating MJ, Montserrat E, Rai KR, Kipps TJ. Guidelines for the diagnosis and treatment of chronic lymphocytic leukemia: a report from the International Workshop on Chronic Lymphocytic Leukemia updating the National Cancer InstituteWorking Group 1996 guidelines. Blood 2008;111(12):5446-56.

46. Bystry V, Agathangelidis A, Bikos V, Sutton LA, Baliakas $P$, Hadzidimitriou A, Stamatopoulos K, Darzentas N. ARResT/ AssignSubsets: a novel application for robust subclassification of chronic lymphocytic leukemia based on B cell receptor IG stereotypy. Bioinformatics 2015;31(23):3844-6.

47. Malcikova J, Tausch E, Rossi D, Sutton LA, Soussi T, Zenz T, Kater AP, Niemann CU, Gonzalez D, Davi F, Gonzalez Diaz M, Moreno C, Gaidano G, Stamatopoulos K, Rosenquist R, Stilgenbauer S, Ghia P, Pospisilova S. ERIC recommendations for TP53 mutation analysis in chronic lymphocytic leukemia-update on methodological approaches and results interpretation. Leukemia 2018;32(5):1070-80.

48. Malcikova J, Stano-Kozubik K, Tichy B, Kantorova B, Pavlova S, Tom N, Radova L, Smardova J, Pardy F, Doubek M, Brychtova Y, Mraz M, Plevova K, Diviskova E, Oltova A, Mayer J, Pospisilova S, Trbusek M. Detailed analysis of therapy-driven clonal evolution of TP53 mutations in chronic lymphocytic leukemia. Leukemia 2015;29(4):877-85

49. Baliakas $P$, Iskas $M$, Gardiner $A$, Davis $Z$, Plevova K, Nguyen-Khac $F_{\text {, }}$ Malcikova J, Anagnostopoulos A, Glide S, Mould S, Stepanovska K, Brejcha M, Belessi C, Davi F, Pospisilova S, Athanasiadou A, Stamatopoulos K, Oscier D. Chromosomal translocations and karyotype complexity in chronic lymphocytic leukemia: a systematic reappraisal of classic cytogenetic data. Am J Hematol 2014;89(3):249-55

50. Baliakas $P$, Jeromin $S$, Iskas $M$, Puiggros A, Plevova K, Nguyen-Khac $F_{\text {, }}$ Davis Z, Rigolin GM, Visentin A, Xochelli A, Delgado J, Baran-Marszak F, Stalika E, Abrisqueta P, Durechova K, Papaioannou G, Eclache V, Dimou M, lliakis T, Collado R, Doubek M, Calasanz MJ, Ruiz-Xiville $\mathrm{N}$, Moreno C, Jarosova M, Leeksma AC, Panayiotidis P, Podgornik H, Cymbalista F, Anagnostopoulos A, Trentin L, Stavroyianni N, Davi F, Ghia P, Kater AP, Cuneo A, Pospisilova S, Espinet B, Athanasiadou A, Oscier D, Haferlach C, Stamatopoulos K. Cytogenetic complexity in chronic lymphocytic leukemia: definitions, associations, and clinical impact. Blood 2019;133(11):1205-16.

51. Xochelli A, Baliakas P, Kavakiotis I, Agathangelidis A, Sutton LA, Minga E, Ntoufa S, Tausch E, Yan XJ, Shanafelt T, Plevova K, Boudjogra M, Rossi D, Davis Z, Navarro A, Sandberg Y, Vojdeman FJ, Scarfo L, Stavroyianni N, Sudarikov A, Veronese S, Tzenou T, Karan-Djurasevic T, Catherwood M, Kienle D, Chatzouli M, Facco M, Bahlo J, Pott C, Pedersen LB, Mansouri L, Smedby KE, Chu CC, Giudicelli V, Lefranc
MP, Panagiotidis P, Juliusson G, Anagnostopoulos A, Vlahavas I, Antic D, Trentin L, Montillo M, Niemann C, Dohner H, Langerak AW, Pospisilova S, Hallek M, Campo E, Chiorazzi N, Maglaveras N, Oscier D, Gaidano G, Jelinek DF, Stilgenbauer S, Chouvarda I, Darzentas N, Belessi C, Davi F, Hadzidimitriou A, Rosenquist R, Ghia P, Stamatopoulos K. Chronic Lymphocytic Leukemia with Mutated IGHV4-34 Receptors: Shared and Distinct Immunogenetic Features and Clinical Outcomes. Clin Cancer Res 2017;23(17):5292-301.

52. Kostareli E, Gounari M, Agathangelidis A, Stamatopoulos K. Immunoglobulin gene repertoire in chronic lymphocytic leukemia: Insight into antigen selection and microenvironmental interactions. Mediterr J Hematol Infect Dis 2012;4(1):e2012052.

53. Gaidano G, Rossi D. The mutational landscape of chronic lymphocytic leukemia and its impact on prognosis and treatment. Hematol Am Soc Hematol Educ Progr 2017;2017(1):329-37.

54. Langerak AW, Davi F, Ghia P, Hadzidimitriou A, Murray F, Potter KN, Rosenquist R, Stamatopoulos K, Belessi C. Immunoglobulin sequence analysis and prognostication in CLL: guidelines from the ERIC review board for reliable interpretation of problematic cases. Leukemia 2011;25(6):979-84.

55. Visco C, Moretta F, Falisi E, Facco M, Maura F, Novella E, Nichele I, Finotto S, Giaretta I, Ave E, Perbellini O, Guercini N, Scupoli MT, Trentin L, Trimarco V, Neri A, Semenzato G, Rodeghiero F, Pizzolo G, Ambrosetti A. Double productive immunoglobulin sequence rearrangements in patients with chronic lymphocytic leukemia. Am J Hematol 2013;88(4):277-82.

56. Mimmi S, Vecchio E, laccino E, Rossi M, Lupia A, Albano F, Chiurazzi F, Fiume G, Pisano A, Ceglia S, Pontoriero M, Golino G, Tassone P, Quinto I, Scala G, Palmieri C. Evidence of shared epitopic reactivity among independent B-cell clones in chronic lymphocytic leukemia patients. Leukemia 2016;30(12):2419-22.

57. Damm F, Mylonas E, Cosson A, Yoshida K, Della Valle V, Mouly E, Diop M, Scourzic L, Shiraishi Y, Chiba K, Tanaka H, Miyano S, Kikushige $Y$, Davi F, Lambert J, Gautheret D, Merle-Beral H, Sutton L, Dessen P, Solary E, Akashi K, Vainchenker W, Mercher T, Droin N, Ogawa S, Nguyen-Khac F, Bernard OA. Acquired initiating mutations in early hematopoietic cells of CLL patients. Cancer Discov 2014;4(9):1088101.

58. Kikushige Y, Ishikawa F, Miyamoto T, Shima T, Urata S, Yoshimoto G, Mori Y, lino T, Yamauchi T, Eto T, Niiro H, Iwasaki H, Takenaka K, Akashi $\mathrm{K}$. Self-renewing hematopoietic stem cell is the primary target in pathogenesis of human chronic lymphocytic leukemia. Cancer Cell 2011;20(2):246-59.

59. Mozessohn L, Earle C, Spaner D, Cheng SY, Kumar M, Buckstein R. The Association of Dyslipidemia With Chronic Lymphocytic Leukemia: A Population-Based Study. J Natl Cancer Inst 2017;109(3).

60. Rawstron AC, Yuille MR, Fuller J, Cullen M, Kennedy B, Richards SJ, Jack AS, Matutes E, Catovsky D, Hillmen P, Houlston RS. Inherited predisposition to CLL is detectable as subclinical monoclonal B-lymphocyte expansion. Blood 2002;100(7):2289-90.

61. Lanasa MC, Allgood SD, Volkheimer AD, Gockerman JP, Whitesides JF, Goodman BK, Moore JO, Weinberg JB, Levesque MC. Single-cell analysis reveals oligoclonality among "low-count" monoclonal B-cell lymphocytosis. Leukemia 2010;24(1):133-40.

62. Baliakas $P$, Agathangelidis A, Hadzidimitriou A, Sutton LA, Minga E, Tsanousa A, Scarfo L, Davis Z, Yan XJ, Shanafelt T, Plevova K, Sandberg Y, Vojdeman FJ, Boudjogra M, Tzenou T, Chatzouli M, Chu CC, Veronese S, Gardiner A, Mansouri L, Smedby KE, Pedersen LB, Moreno D, Van Lom K, Giudicelli V, Francova HS, Nguyen-Khac F, Panagiotidis $P$, Juliusson $G$, Angelis $L$, Anagnostopoulos A, Lefranc MP, Facco M, Trentin L, Catherwood M, Montillo M, Geisler CH, Langerak AW, Pospisilova S, Chiorazzi N, Oscier D, Jelinek DF, Darzentas N, Belessi C, Davi F, Ghia P, Rosenquist R, Stamatopoulos K. Not all IGHV3-21 chronic lymphocytic leukemias are equal: prognostic considerations. Blood 2015;125(5):856-9.

63. Mansouri L, Sutton LA, Ljungstrom V, Bondza S, Arngarden L, Bhoi S, Larsson J, Cortese D, Kalushkova A, Plevova K, Young E, Gunnarsson R, Falk-Sorqvist E, Lonn P, Muggen AF, Yan XJ, Sander B, Enblad G, Smedby KE, Juliusson G, Belessi C, Rung J, Chiorazzi N, Strefford JC, Langerak AW, Pospisilova S, Davi F, Hellstrom M, Jernberg-Wiklund $\mathrm{H}$, Ghia P, Soderberg O, Stamatopoulos K, Nilsson M, Rosenquist R. Functional loss of IkappaBepsilon leads to NF-kappaB deregulation in aggressive chronic lymphocytic leukemia. J Exp Med 2015;212(6):833-43.

64. Rossi D, Spina V, Cerri M, Rasi S, Deambrogi C, De Paoli L, Laurenti L, 
Maffei R, Forconi F, Bertoni F, Zucca E, Agostinelli C, Cabras A, Lucioni M, Martini M, Magni M, Deaglio S, Ladetto M, Nomdedeu JF, Besson C, Ramponi A, Canzonieri V, Paulli M, Marasca R, Larocca LM, Carbone A, Pileri SA, Gattei V, Gaidano G. Stereotyped B-cell receptor is an independent risk factor of chronic lymphocytic leukemia transformation to Richter syndrome. Clin Cancer Res 2009;15(13):4415-22.

65. Sutton LA, Young E, Baliakas P, Hadzidimitriou A, Moysiadis T, Plevova K, Rossi D, Kminkova J, Stalika E, Pedersen LB, Malcikova J, Agathangelidis A, Davis Z, Mansouri L, Scarfo L, Boudjoghra M, Navarro A, Muggen AF, Yan XJ, Nguyen-Khac F, Larrayoz M Panagiotidis $P$, Chiorazzi N, Utoft Niemann C, Belessi C, Campo E, Strefford JC, Langerak AW, Oscier D, Gaidano G, Pospisilova S, Davi F, Ghia P, Stamatopoulos K, Rosenquist R. Different spectra of recurrent gene mutations in subsets of chronic lymphocytic leukemia harboring stereotyped B-cell receptors. Haematologica 2016;101(8):959-67. 66. Santambrogio E, Orsucci L. Helicobacter pylori and hematological disorders. Minerva Gastroenterol Dietol 2019 Apr 16. [Epub ahead of print] doi:10.23736/s1121-421x.19.02580-7.

\section{SUPPLEMENTAL MATERIAL}

The online version of this article (doi: 10.5507/ bp.2019.046) offers supplemental material. 